\title{
Hepatoprotective and Antioxidant Role of Ziziphus jujuba Leaves on Paracetamol Induced Hepatic Damage in Rats
}

\author{
J. Preethi ${ }^{1}$, K. Vennila ${ }^{1}$, S. Penislusshiyan ${ }^{2}$, S. Velvizhi ${ }^{1}{ }^{*}$ \\ ${ }^{1}$ Department of Biochemistry, Biotechnology, Bioinformatics, Avinashilingam Institute for Home Science and Higher Education for Women, \\ Coimbatore, India \\ ${ }^{2}$ Department of Biochemistry, Periyar University, Salem, Tamil Nadu, India
}

\section{Email address:}

velvizhi_bc@avinuty.ac.in (S. Velvizhi),sri.Velvizhi@gmail.com (S. Velvizhi)

\section{To cite this article:}

J. Preethi, K. Vennila, S. Penislusshiyan, S. Velvizhi. Hepatoprotective and Antioxidant Role of Ziziphus jujuba Leaves on Paracetamol Induced Hepatic Damage in Rats. Journal of Diseases and Medicinal Plants. Special Issue: Pharmacological Action of Medicinal Plants: Health and Diseases. Vol. 2, No. 1-1, 2016, pp. 1-10. doi: 10.11648/j.jdmp.s.2016020101.11

\begin{abstract}
To evaluate the hepatoprotective activity of aqueous extract of Ziziphus jujuba leaves against paracetamol-induced liver injury in experimental rats. Ziziphus jujuba has been traditionally used in the Ayurvedic system of medicine as a chief ingredient in many polyherbal formulations as antioxidant. To evaluate the antioxidant and hepatoprotective activity of aqueous leaf extract of Ziziphus jujuba leaves. Animals were pre-treated with the aqueous leaf extract for 7 days and then toxicity was induced with a single paracetamol oral injection. Pre-treatment with $150 \mathrm{mg} / \mathrm{kg}$ of aqueous leaf extract of Ziziphus jujuba improved the reduced glutathione (oxidized), SOD, catalase, and peroxidase levels significantly as compared to control group. Silymarin was used as standard reference and exhibited significant hepatoprotective activity against paracetamol induced hepatotoxicity in rats. The biochemical observation was reported for rat liver sections. The results of this study strongly indicate that Ziziphus jujuba leaves have potent hepatoprotective action against paracetamol induced hepatic damage in rats. Aqueous extract was found more potent hepatoprotective. Meanwhile, in vivo antioxidant activities were also screened which were positive for aqueous extracts. On the basis of this study, we conclude that aqueous extract of Ziziphus jujuba possesses in vivo antioxidant activity and can be employed in protecting tissues from oxidative damage and stress.
\end{abstract}

Keywords: Ziziphus jujuba, Silymarin, Paracetamol, Biochemical Markers, Hepatoprotective

\section{Introduction}

The liver is one of the largest organs in human body associated with assorted stages of metabolic and physiologic homeostasis of the organism and the preeminent site for intense metabolism and excretion. So it has a stunning role in the maintenance, performance and regulating homeostasis of the body. It is involved through almost all the biochemical pathways to growth, fight and several imperative functions related to digestion, metabolism, immunity and storage of nutrients [1]. But it is continuously and variedly disclosed to environmental toxins, free radicals, alcohol, xenobiotics, food additives and persecuted by poor drug usages like alcohol and arbitrary over-the counter drug which can eventually lead to numerous liver ailments like hepatitis, cirrhosis and alcoholic liver disease [2, 3].

Liver ailments are intermittently caused by hepatitis A, B and $\mathrm{C}$ viruses, carbon tetrachloride $\left(\mathrm{CCl}_{4}\right)$, high doses of paracetamol, thioacetamide (TAA) and convinced chemotherapeutic agents [4]. Acetaminophen (N-acetyl-paminophenol, paracetamol) induced toxicity in rats is one of the extensively used experimental model to evaluate the hepatoprotective activity of plant extracts $[5,6]$. It has been opinioned in recent reports that $10 \%$ of world population are affected with liver diseases along with hepatitis, alcoholic steatosis, fibrosis, liver cirrhosis and hepatocellular carcinoma. Morbidity and mortality resulting from liver diseases are a major social health complication worldwide [7].

The main function of the liver is to expel toxic substances from the blood stream. This process may be interrupted it toxins prepare to enter the blood stream at a rate faster than the liver's ability to break them down and this can cause liver toxicity [8]. Increase the level of liver enzymes ALT and AKP in serum in combination with increased bilirubin level are 
literally considered to be the most relevant signal of liver toxicity it includes,

\section{i. Hepatocellular toxicity}

ALT is considered a most peculiar and sensitive indicator of hepatocellular injury than AST. An increase in ALT activity in the range of 2-4 folds and higher compared to control average should rise concern as a proof of potential hepatic injury [9].

\section{ii. Hepatobiliary toxicity}

Initial assessment of Hepatobiliary damage in rats can be consummated by measuring serum concentrations of bile acids and bilirubin, serum activities of liver correlated enzymes such as ALP, $\gamma$ - glutamyl transpeptidase and plasma clearances of dyes excreted primarily through the bile [10].

The cells in the liver encompass proteins called enzymes that drive these chemical reactions when liver cells are impaired or destroyed the enzymes in the cells leak out into the blood where they can be measured by liver enzymes are ALT, AST, etc. If ALT and AST are found together in exalted amounts in the blood, liver damage is most likely present.

Hepatotoxicity signifies chemical driven liver damage. The liver plays a central aspect in transforming and clearing chemicals and is susceptible to the toxicity from these agents certain medicinal agents, when taken in overdoses and sometimes even when introduced within therapeutic ranges, may damage the organ. Other chemical agents such as those used in laboratories, industries, natural chemicals (Eg. Microcystins) and herbal remedies can also prompt hepatotoxicity. Chemicals on the way to cause liver injury are called hepatotoxins [11]. Elderly persons are at increased opportunity of hepatic injury because of decreaed clearance, drug to drug interactions reduced hepatic blood flow variation in drug binding poor diet, infections and multiple hospitalizations are important logics for drug induced Hepatotoxicity. Hepatic drug reactions are more familiar in females [12]. Most of the hepatotoxic chemical damage, liver cells mainly by engendering lipid peroxidation and other oxidative damage [13].

Treatment of diseases associated with the liver is mandatory, and must be done with convenient and extensive care. There are few conventional drugs that can stimulate liver function and offer hepatic protection or help in the reclamation of hepatic cells, but they are proved to be hepatotoxic at a particular dose [14].

At therapeutic doses, paracetamol is considered a secure drug at the same time a number of reporters indicate that overdose of paracetamol can produce centrizonal haemorrhagic hepatic necrosis, nephrotoxicity, extra hepatic lesions, and even death in humans and experimental animals [15]. The best amount of paracetamol for adults is 1 gram $(1000 \mathrm{mg})$ per dose and 4 grams (4000 mg) per day. Taking extra paracetamol could cause damage to your liver [16]. Paracetamol is the most common drug taken in over dose resulting toxic metabolites can cross the placenta and lead to hepatocellular necrosis of maternal and fetal liver cells during pregnancy [17]. Paracetamol toxicity is caused by the reaction metabolite $\mathrm{N}$ acetyl-p-benzoquinoneimine (NAPQI) which is partially metabolized by cytochrome $\mathrm{P}_{450}$ [18]. NAPQI is originally detoxified by conjugation with reduced glutathione (GSH) to form mercapturic acid. However the rate of NAPQI formation outstrips the rate of detoxification by GSH, it oxidizes tissue macromolecules such as lipid or - $\mathrm{SH}$ group of protein and modifies the homeostasis of calcium after depleting GSH [19]. So there is a demand to evaluate natural compounds as effective alternatives.

Liver disease is still a global health problem. Unfortunately, conventional or synthetic drugs used in the treatment of liver disorders are inadequate and sometimes can have serious side effects. In the absence of a consistent liver protective drug in modern medicine, there are a number of medicinal preparations in Ayurveda recommended for the healing of liver disorders [20]. In allopathic medicinal practices consistent liver protective drugs are not available, but herbs play a major role in the management of liver disorders [21]. In view of severe undesirable side effects of synthetic agents, there is an emergent focus to follow the systematic research methodology and to evaluate the scientific source for the traditional herbal medicines that are claimed to acquire hepatoprotective activity.

Only a few modern drugs are applicable for treating liver diseases. Drugs such as tricholine citrate, trithioparamethoxy phenyl propene, and essential phospholipids, combination of Lornithine L-aspartate and pancreatin, silymarin and ursodesoxy cholic acid are universally prescribed for hepatitis, cirrhosis and other liver diseases. However, these modernized medical treatments are still far from satisfactory. Management of liver disease is still a challenge to the current medicine. In the absence of consistent liver-protective drugs in the allopathic medical practices, herbs show a vital role in the management of liver disorders. Many indigenous plants are used for the therapy of liver disorders.

Himoliv (HV) is a multi-herbal formulation, containing aqueous extracts of 25 endemic medicinal plants. $\mathrm{HV}$ is also declared to be useful in the treatment of hepatitis, jaundice, biliary dysfunction and liver disorder. Oxidative damage through free radical generation is among the distinct mechanisms involved in the hepatotoxic effect of carbon tetrachloride $\left(\mathrm{CCl}_{4}\right)$ and paracetamol $(\mathrm{PC})$. An anti-oxidant property is declared to be one of the mechanisms of hepatoprotective effect of the test drug [22].

Herbal medicine is an achievement of popular therapeutic diversity [23]. The world is now touching towards the herbal medicine or system, which can then properly fight foreign invaders and aid to destroy offending pathogens without toxic side-effects [24]. The world health organization in the early 1970 's had an expectant government to effectively utilize local knowledge of herbal medicines for disease anticipation and health promotion [25]. WHO has shown great curiosity in documenting the use of medicinal plants used by tribal's from different parts of the world [26]. At present this herbal medicine is coming into prominence because of the efficiency of the conventional medicines such as antibiotics, which have developed resistance to the many of the transmittable organisms, whereas herbs and its active constituents are being 
used to treat the infections, which no longer responsive to conventional medicine. The unique feature of traditional medicine in India is that it flourishes at several levels. Herbal medicines are cheaper, easily accessible and their method of preparation is also trouble-free and above all it suits the societal and cultural needs of peoples [27]. Silymarin is promoted as one of the standard hepatoprotective herbal formulations.

Among the medicinal plants, Ziziphus jujuba (family: Rhamnaceae) is a useful Indian medicinal plant which has been qualified with therapeutic properties to treat several diseases. Ziziphus jujuba is a deciduous tree growing to $10 \mathrm{~m}(32 \mathrm{ft})$ by $7 \mathrm{~m}(23 \mathrm{ft})$ at a rapid rate. It is tough to zone. It is in flower from April to May, and the seeds ripen during October. The flowers are hermaphrodite (have both male \& female organs) and are pollinated through insects. It is a self fertile plant [28]. Suitable for light (sandy) medium (loamy) and heavy (clay) soils, desires well drained soil and can grow in nutritionally poor soil. Suitable pH: acid, neutral and basic (alkaline) soils and can grow in incredibly alkaline soils.

It cannot grow up in the shade, it prefers dry or moist soil and can tolerate drought. It functions as anodyne, antidote, astringent, emollient, expectorant, hypnotic, narcotic, pectoral, tranquillizer and diuretic, it is used to treat cancer, skin and GI tract diseases. An active and safe drug is needed for the treatment of liver disorders. Jujuba is an effectual herbal remedy. It supports weight gain, improves muscular strength and increases stamina. In Chinese medicine jujuba was prescribed as a tonic to strengthen liver function. The leaves are astringent and febrifuge it is also said to promote hair growth [29]. Jujuba helps to resourcefully get the energy from food. It also gives energy and has an emotionally calming effect. In-vivo experiments illustrate that Z.jujuba can increase the phagocytosis of mice's mononuclear-phagocyte system [30]. The seed is hypnotic and tonic. The root is used to treat the dyspepsia. The leaves are applied as poultices and are helpful in liver troubles, asthma and fever and it also strengthens liver function and stimulates immune system [31], the leaves are antipyretic and diminish obesity [32]. Extracts of jujuba leaves can appreciably inhibit dimethyl benzene-induced auricular inflammation in mice. They are used to form a plaster in the treatment of strangury [33]. Ziziphin, a compound in the leaves of the jujube, stifles the ability to perceive the sweet taste in humans. The plant is unanimously called as "Ilantai".

Hence, the aim of the present study was to investigate the hepatoprotective effects of crude aqueous extracts of $Z$. jujuba leaves on paracetamol induced hepatotoxicity in albino rats. The protective effects were compared with silymarin, a well known hepatoprotective agent against paracetamol induced hepatotoxicity.

\section{Materials and Methods}

The study was undertaken to evaluate the antioxidant and hepatoprotective activity on leaves of Ziziphus jujuba under the following.

\subsection{Drugs and Chemicals}

Silymarin, SGOT, SGPT, ALP, kits were purchased from Sigma, Tamilnadu, India. 5, 5'-dithiobis-2-nitrobenzoic acid (DTNB), Reduced Glutathione (GSH) and the rest of the chemicals utilized were of analytical grade and were obtained from Himedia, India.

\subsection{Collection of Plant Materials}

The leaves of Ziziphus jujuba used in this study were collected fresh during the month of December to January in Bommidi TK, Dharmapuri district of Tamilnadu.

\subsection{Preparation of Extract}

$15 \mathrm{~g}$ of the powdered sample was taken in a thimble and placed in a Soxhlet apparatus and was extracted by the hot percolation method. Using $250 \mathrm{ml}$ of solvents with increasing polarity namely chloroform. The extract was carried out until the plant material, become colourless. The extract was collected and evaporated in a boiling water bath at $60^{\circ} \mathrm{C}$. The residue was mashed and stored in an airtight container in a refrigerator.

An aqueous extract of the plant sample also prepared as follows, to about $1 \mathrm{~g}$ of the powdered sample, added $100 \mathrm{ml}$ of distilled water and kept in a water bath at $60^{\circ} \mathrm{C}$ for $2 \mathrm{hrs}$. Filtered and centrifuged thrice, and the supernatant was collected and stored in an airtight contai6ner in the refrigerator for further study.

\subsection{Experimental Design}

The present study was conducted out in 3 phases.

Phase I: Preliminary Phytochemical analysis of the plant extract.

Phase II: Assessment of Enzymatic and non enzymatic antioxidant activity of the plant extract.

Phase III: Hepatoprotective effect of the plant extract which was tested in an experimental rats.

PHASE I: Preliminary Phytochemical Analysis of the Plant Extract

The qualitative analysis was carried out for the presence of Proteins, Carbohydrates, Alkaloids, Flavonoids, Saponins, Phenols, Glycosides, Tannins, Phytosterols, Terpenoids and Anthroquinones was done by using method of [34-37], in Ziziphus jujuba leaf extract.

Phase II: Assessment of Enzymatic and non enzymatic Antioxidant Activity of the plant Extract:

The leaves of Ziziphus jujuba were analyzed for the enzymatic and non enzymatic antioxidants such as catalase, peroxidase, superoxide dismutase, polyphenol oxidase reduced glutathione and polyphenol.

Estimation of Catalase Activity: To measure the catalase the sample was homogenized in a pre chilled mortar and pestle with $0.067 \mathrm{M}$ phosphate buffer at $1-4^{\circ} \mathrm{C}$ and centrifuged. Stirred the sediment with cold phosphate buffer, allowed to stand in the cold with occasional shaking and then repeated the 
extraction once or twice. The extraction should not take more than 24hours. The combined supernatants were used for the assay.

Assay: Pipetted out $3.0 \mathrm{ml}$ of $\mathrm{H}_{2} \mathrm{O}_{2}$ Phosphate buffer into the experimental cuvette. Mixed with $0.01-0.04 \mathrm{ml}$ of sample with a glass rod flattened at one end. Noted the time $\Delta t$ required for a decrease in absorbance from 0.45 to 0.4 at $240 \mathrm{~nm}$. This value was used for the calculation. If $\Delta \mathrm{t}$ was greater than 60 seconds, then repeated the measurements with a more concentrated solution of the sample. Calculated the activity and expressed in units per mg protein. One enzyme unit was calculated as the amount of enzyme required to decrease the absorbance at $240 \mathrm{~nm}$ by 0.05 units.

Calculation: Calculated the concentration of $\mathrm{H}_{2} \mathrm{O}_{2}$ using the extinction coefficient $0.036 \mu \mathrm{mole} / \mathrm{ml}$ [38].

Estimation of Peroxidase Activity:

Enzyme extract: To estimate the peroxidase activity measured one gram of the sample with $5 \mathrm{ml}(\mathrm{w} / \mathrm{v}) 0.1$ phosphate buffer ( $\mathrm{pH}$ 6.5) in a homogenizer. Centrifuge the homogenate at $300 \mathrm{~g}$ for 15 minutes. Use the supernatant as the enzyme source. All procedures were carried out in $0-50^{\circ} \mathrm{C}$.

Procedure: Pipetted out $3 \mathrm{ml}$ of $0.05 \mathrm{M}$ - Pyrogallol solution and 0.5 to $0.1 \mathrm{ml}$ of enzyme extract in a test tube. Adjust the spectrophotometer to read ' 0 ' at $400 \mathrm{~nm}$. Add $0.5 \mathrm{ml}$ of $1 \%$ $\mathrm{H}_{2} \mathrm{O}_{2}$ in the cuvette. Record the change in the absorbance every 30 seconds up to 3 minutes [39].

Assay of Superoxide Dismutase (SOD)

Procedure: To estimate the SOD activity the incubation medium contained $300 \mu 1$ of each reagent $(50 \mathrm{mM}$ potassium phosphate buffer, $45 \mu \mathrm{M}$ Methionine, $5.3 \mu \mathrm{M}$ Riboflavin, $84 \mu \mathrm{M}$ NBT and $20 \mathrm{mM}$ potassium cyanide). To the test $300 \mu \mathrm{l}$ of sample was added and the final volume was made up to $3 \mathrm{ml}$ with distilled water. The tubes were placed in an aluminium foil-lined box maintained at $25^{\circ} \mathrm{C}$ and equipped with $15 \mathrm{~W}$ fluorescent lamps. Reduced NBT was measured spectrophotometrically at $600 \mathrm{~nm}$ after exposure to light for 10 minutes. The maximum reaction was evaluated in the absence of enzymes. One unit of enzyme activity is defined as the enzyme reaction, which gives $50 \%$ inhibition of NBT reduction in one minute under the assay conditions and expressed as specific activity in units [40].

Estimation of Polyphenol Oxidase (PPO) Activity

Preparation of enzyme extract: To estimate the polyphenol oxidase ground about $5 \mathrm{~g}$ of the tissue and made up to $20 \mathrm{ml}$ with the medium containing 50mM Tris - HCL ( $\mathrm{pH} 7.2$ ), $0.4 \mathrm{M}$ sorbital and $10 \mathrm{Mm}$ Nacl. Centrifuged the homogenate at 2000rpm for $10 \mathrm{~min}$ and used the supernatant for the assay.

Procedure: Added $2.5 \mathrm{ml}$ of $0.2 \mathrm{M}$ phosphate buffer ( $\mathrm{pH} 6.5$ ), $0.3 \mathrm{ml}$ of catechol solution $(0.01 \mathrm{M})$ into the cuvette and set the spectrophotometer at $495 \mathrm{~nm}$. Now added the enzyme extract $(0.2 \mathrm{ml})$ and started recording the change in absorbance for every 30 seconds up to 5 minutes [41].

\section{Estimation of Reduced Glutathione}

Procedure: To estimate the reduced glutathione $1 \mathrm{~g}$ of the sample was homogenized in 5\% TCA to give $20 \%$ homogenate. The precipitated protein was centrifuged down at
$1000 \mathrm{rpm}$ for 10 minutes. The homogenate was cooled on ice and $0.1 \mathrm{ml}$ of the supernatant was taken for the estimation. The volume of the aliquot was made up to $1.0 \mathrm{ml}$ with $0.2 \mathrm{M}$ Sodium phosphate buffer ( $\mathrm{pH} 8.0), 2 \mathrm{ml}$ of freshly prepared DTNB solution $(0.6 \mathrm{mM}$ in $0.2 \mathrm{M}$ phosphate buffer-pH 8.0$)$ was added to the tubes and the intensity of the yellow colour formed was read at $412 \mathrm{~nm}$ in a spectrophotometer after 10 minutes. A standard curve of reduced glutathione was prepared using concentrations ranging from 2 to 10 nanomoles of reduced glutathione in 5\% TCA [42].

\section{Estimation of Polyphenols}

Procedure: To estimate the polyphenol $1 \mathrm{~g}$ of the sample was homogenized using $20 \mathrm{ml}$ of $80 \%$ ethanol. The homogenate was centrifuged at $10,000 \mathrm{rpm}$ for 20 minutes. The supernatant was saved. The residue was extracted with $10 \mathrm{ml}$ of $80 \%$ ethanol, centrifuged and collected the supernatant and evaporated to dryness. The residue was dissolved in a known volume of distilled water $(50 \mathrm{ml})$ and $2.0 \mathrm{ml}$ was taken for the experiment. A working standard of $0.5-2.5 \mathrm{ml}$ catechol solution corresponding to $50-250 \mu \mathrm{g}$ of catechol were pipetted out into a series of test tubes. The volume was made up to $2.5 \mathrm{ml}$ with water. To all the tubes added $0.5 \mathrm{ml}$ of diluted Folin Ciocalteau reagent. After 3 minutes, added $2.0 \mathrm{ml}$ of $20 \%$ $\mathrm{Na}_{2} \mathrm{CO}_{3}$ solution to each tube and mixed thoroughly.

The tubes were placed in a boiling water bath for exactly one minute. Cooled and measured at $650 \mathrm{~nm}$ against a reagent blank. Construct a standard graph by plotting the concentration of catechol on X-axis and absorbance on Y-axis. From the graph, the amount of polyphenols present in the sample was estimated and expressed as $\mathrm{mg}$ of polyphenols per $\mathrm{g}$ of the sample [43].

PHASE III: Hepatoprotective Effect of the Plant Extract:

Paracetamol induced hepatotoxicity in rats were used as a model to conclude the hepatoprotective activity of aqueous extract of Ziziphus jujuba leaves [44]. Calculated amount of dried aqueous extract was suspended in to get the test doses $(150 \mathrm{mg} / \mathrm{kg})$.

\subsection{Selection and Grouping of Animals}

Healthy albino rats of Wistar strain weighing between 115$135 \mathrm{~g}$ were selected and obtained from small animal breeding station Thrisur, Kerala and were acclimatized to the laboratory condition $(12+1 \mathrm{hr}$, day and night schedule; temperature maintained between $11-20^{\circ} \mathrm{C}+2{ }^{\circ} \mathrm{C}$; housed in large hygienic plastic cages) and each group contains 4 rats. Before a week of the experiment water and natural pellets were provided throughout the experimental period. All the experiments were performed with the permission from the Institutional Animal Ethics Committee and were in accordance with the guidelines of CPCSEA.

The Animals were divided into 4 main groups:

Group I: Control, normal healthy rats

Group II: Toxic control (Paracetamol) (750mg/kg b.weight) given orally on day 1 to day7.

Group III: Aqueous extract $(150 \mathrm{mg} / \mathrm{kg}$ of b.weight) given 
orally on day 1 to day 7 along with paracetamol $(750 \mathrm{mg} / \mathrm{kg}$ b.weight) [45].

Group IV: Silymarin ( $25 \mathrm{mg} / \mathrm{kg}$ of $\mathrm{b}$. weight) given orally as standard for seven days along with paracetamol $(750 \mathrm{mg} / \mathrm{kg}$ b.weight) [46].

Before treatment the rats were fasted overnight with free admission to the water. On the $7^{\text {th }}$ day of the study the animals were sacrificed and liver and blood samples were collected from each animal to generate the liver and serum biochemical assay.

\subsection{Preparation of the Sample for Biochemical Analysis}

Each individual animal has a liver were removed and stored. A part of the liver was washed with ice cold PBS, blotted dry and the homogenate was prepared using phosphate buffered saline ( $\mathrm{pH}$ 7.2). The biochemical parameters were considered,

*AST (SGOT)

*ALT (SGPT)

*ALP (Alkaline phosphatase)

The blood samples after coagulation were centrifuged at 3000rpm for 15-20 minutes and the isolated sera were used for assessment of the biochemical markers of liver damage [45].

The liver tissues of the animals were surgically removed blotted and weighed. $0.5 \mathrm{~g}$ was crushed in a mortar and then homogenized in phosphate buffer, it was centrifuged at 2000rpm for 20 minutes in a refrigerated centrifuge. The supernatant was immediately used for assay of liver marker enzymes.

Determination of the Biochemical Parameters:

\section{Estimation of Aspartate transaminase:}

Aspartate transaminase in both serum and liver was determined by the manner of Reitman's and Frankel, 1957 [47]. $0.5 \mathrm{ml}$ of buffered substrate was incubated at $37^{\circ} \mathrm{C}$ for 3 minutes and $0.1 \mathrm{ml}$ of serum was added, mixed well and incubated at $37^{\circ} \mathrm{C}$ for 30 minutes. Then $0.5 \mathrm{ml}$ of 2,4 dinitrophenyl hydrazine reagent was added, mixed well and kept at room temperature for 20 minutes and $0.5 \mathrm{ml}$ of $4 \mathrm{~N}$ working sodium hydroxide was added and kept at room temperature for 10 minutes. Blank and standards were also processed in a similar way and the absorbance was measured spectrophotometrically at $505 \mathrm{~nm}$.

\section{Estimation of Alanine transaminase:}

Alanine transaminase in both serum and liver were determined by the manner of Reitman's and Frankel, 1957 [47]. $0.5 \mathrm{ml}$ of buffered substrate was incubated at $37^{\circ} \mathrm{C}$ for 3 minutes and $0.1 \mathrm{ml}$ of serum was added, mixed well and incubated at $37^{\circ} \mathrm{C}$ for 60 minutes. Then $0.5 \mathrm{ml}$ of 2,4 dinitrophenyl hydrazine reagent was added, mixed well and kept at room temperature for 20 minutes and $0.5 \mathrm{ml}$ of $4 \mathrm{~N}$ working sodium hydroxide was added and kept at room temperature for 10 minutes. Blank and standards were also processed in a similar way and the absorbance was measured spectrophotometrically at $505 \mathrm{~nm}$. The activity of SGPT was expressed as IU/L.

Estimation of Alkaline phosphastase:

Alkaline phosphatase in both serum and liver were determined by the manner of King and Amstrong, 1934 [48]. $4 \mathrm{ml}$ of substrate was a pipette out in tubes marked as test and control. They were placed in a boiling water bath at $37^{\circ} \mathrm{C}$ for a few minutes. $0.2 \mathrm{ml}$ of serum was added only to the test without removing the tubes from the water bath. Incubate for 15 minutes at $37^{\circ} \mathrm{C}$. At the end of 15 minutes added $1.8 \mathrm{ml}$ of diluted phenol reagent to all tubes. Then $0.2 \mathrm{ml}$ of serum was added to the tubes marked as a control. All the tubes were shaken well and centrifuged. $4 \mathrm{ml}$ of supernatant was taken from each tube. Standards of various concentrations (0.2 $1.0 \mathrm{ml})$ were taken and made up to $2.8 \mathrm{ml}$ with water. $1 \mathrm{ml}$ of sodium carbonate solution was added to all the tubes and the tubes were incubated in a water bath at $37^{\circ} \mathrm{C}$ for 15 minutes. To a blank $2.8 \mathrm{ml}$ of water was added to $1.2 \mathrm{ml}$ of diluted phenol reagent. The activity of ALP was expressed in KA units.

\subsection{Statistical Analysis}

The Statistical significance of the data was assessed by analysis of variance. The toxic control was compared with the normal control group and all other treatment groups were compared with the toxic control group.

\section{Results and Discussion}

The present study had been attempted to demonstrate, "Hepatoprotective and Antioxidant role of Ziziphus jujuba leaves on paracetamol induced hepatic damage in rats" This study was done in different phases shown below:

Phase I: Preliminary phytochemical analysis.

Phase II: Antioxidant activity of aqueous leaf extract of Ziziphus jujuba

Phase III: Assessment of Hepatoprotective activity.

\section{PHASE I}

Preliminary Phytochemical Analysis

For the presence of phytochemicals such as sugars, proteins, terpenoids, alkaloids, phytosterols, anthroquinones, the plant sample was analysed. This activity was analysed in both chloroform and aqueous extract of the plant were shown in table 1 .

Table 1. Qualitative phytochemical analysis in different extract of ziziphus jujuba.

\begin{tabular}{lll}
\hline Plant constituents & Chloroform leaf extract & Aqueous leaf extract \\
\hline Carbohydrate & + & + \\
Protein & + & + \\
Alkaloids & - & + \\
Flavonoids & - & + \\
Saponins & + & + \\
Phenols & + & + \\
Glycosides & - & - \\
Tannins & + & + \\
Phytosterols & + & + \\
Terpenoids & + & + \\
Anthroquinone & - & + \\
\hline
\end{tabular}

(+) Denotes the presence of phytoconstituents

(-) Denotes the absence of phytoconstituents 
The results show that maximum activity of phytoconstituents is seen in the aqueous extract than the chloroform extract of the plant. Thus, for further investigation of antioxidants the aqueous extracts of the plant sample were used and estimated [49]. The phytoconstituents such as Terpenoids, alkaloids and steroids, which are present in the aqueous extract, could be considered to be responsible for the powerful hepatoprotective activity [50].

PHASE II

In vitro Antioxidant Activity on Aqueous Leaf Extract of Ziziphus jujuba.

The Aqueous leaf extract of the plant sample was analysed for the presence of

i) Enzymatic antioxidants (Catalase, Peroxidase, superoxide Dismutase, polyphenol oxidase)

ii) Non Enzymatic antioxidants (Polyphenol, Reduced glutathione)

Enzymatic Antioxidants

Table 2 represents the levels of catalase, peroxidase, SOD and PPO in the leaf extract of Ziziphus jujuba.

Table 2. Enzymatic Antioxidant Activity of Aqueous Leaf Extract of Ziziphus jujuba.

\begin{tabular}{lllll}
\hline & \multicolumn{4}{l}{ ENZYMATIC ANTIOXIDANTS $(\mathrm{mg} / \mathrm{ml})$} \\
\cline { 2 - 5 } S. No & Catalase & Peroxidase & $\begin{array}{l}\text { Superoxide } \\
\text { dismutase }\end{array}$ & $\begin{array}{l}\text { Polyphenol } \\
\text { Oxidase }\end{array}$ \\
\cline { 2 - 5 } & Units */g & Units $* * / g$ & Units $* * * / g$ & Units $++/ g$ \\
\hline 1$)$ & $245.28 \pm 1.426$ & $2.12 \pm 0.006$ & $75.09 \pm 0.75$ & $0.652 \pm 0.003$ \\
\hline
\end{tabular}

Values represent Mean $\pm \mathrm{S}$. D of 2 replicates.

*Unit - Amount of energy required to decrease the absorbance by 0.05 units at $240 \mathrm{~nm}$.

** Unit - Change in absorbance $/ \mathrm{min} / \mathrm{g}$ of sample.

*** Unit -Amount of enzyme that gives $50 \%$ inhibition of the extent of NBT reduction.

++ Unit -n moles of GSH oxidized $/ \mathrm{min} / \mathrm{g}$.

The differences in the mean values among the treatment groups are greater than would be expected by chance, there is a statistically noteworthy difference $(\mathrm{p}=<0.001)$.

From the Table 2 it is evident that the leaf sample exhibits all the above enzyme activities to different levels. The activity of catalase was found to be $245.28 \pm 1.426 \mathrm{U} / \mathrm{g}$ while that of peroxidase was $2.12 \pm 0.006 \mathrm{U} / \mathrm{g}$. The other antioxidant enzymes such as Superoxide dismutase and Polyphenol oxidase have recorded activities $75.09 \pm 0.75 \mathrm{U} / \mathrm{g}$ and $0.652 \pm 0.003 \mathrm{U} / \mathrm{g}$ respectively. Antioxidant enzymes are acknowledged to reduce the harmful effects of free radical [51]. Reduction in the antioxidant defence system eventually causes to lipid peroxidation, protein and DNA Damage [52].

Non Enzymatic Antioxidants

Table 3 indicates the contents of polyphenol and reduced glutathione present in the leaf extract of "Ziziphus jujuba".
Table 3. Non-Enzymatic Antioxidant Activity of Aqueous Leaf Extract of Ziziphus jujuba.

\begin{tabular}{lll}
\hline \multirow{2}{*}{ S. NO } & \multicolumn{3}{l}{ NON-ENZYMATIC ANTIOXIDANTS $(\mathrm{mg} / \mathrm{ml})$} \\
\cline { 2 - 3 } & Reduced Glutathione (n moles/g) & Polyphenol (mg/g) \\
\hline 1$)$ & $1.09 \pm 0.25$ & $1.624 \pm 0.018$ \\
\hline
\end{tabular}

Values are mean $\pm \mathrm{S}$. D of two replicates.

The differences in the mean values among the treatment groups are greater than would be expected by chance. There is a statistically significant difference $(p=<0.001)$.

From the Table 3 it is evident that the leaf sample exhibits all the above enzyme activities to different levels. The activity of reduced glutathione was found to be $1.09 \pm 0.25 \mathrm{n}$ moles $/ \mathrm{g}$ while that of polyphenol was $1.624 \pm 0.018 \mathrm{n}$ moles $/ \mathrm{g}$.

PHASE 3

Assessment of Hepatoprotective Activity:

The Hepatoprotective activity was analysed and the results obtained in the study are discussed under the following headings.

i) Determination of liver weight of Rats

ii) Assessment of serum marker enzymes

iii) Assessment of liver marker enzymes

Determination of Liver Weight of Rats:

The dry weight of the liver from different groups of experimental animals was recorded as given in the Table 4.

Table 4. Weight of the Liver Sample in Different Groups of Rats.

\begin{tabular}{ll}
\hline TREATMENT GROUPS & LIVER WEIGHT (g) \\
\hline I - Control & 8.59 \\
II - Paracetamol Control & 11.08 \\
III - Paracetamol + Plant extract & 8.94 \\
IV - Silymarin+ Paracetamol & 8.72 \\
\hline
\end{tabular}

Values are expressed as mean of 4 rats.

Paracetamol (PCM) induced group confirmed a significant increase in the weight of the liver, which is due to the blocking of the secretion of hepatic triglycerides into plasma. Administration of $750 \mathrm{mg} / \mathrm{kg}$ of PCM in a single oral dose has confirmed to provoke hepatotoxicity in the experimental animals [53].

However the aqueous extract of the leaf sample of Ziziphus jujuba seemed to restrain decrease liver weight in group III when compared to group II. This shows that phytoconstituents and antioxidants in the plant extract maintain proper catabolism of lipids and it prevents their accumulation in the liver.

Assessment of the Serum Marker Enzymes:

High levels of ALT signify liver damage with the highest increases (often $>20$ fold) being observed with acute hepatocellular injuries such as xenobiotics induced neurosis, and it emerges to be a more sensitive test for hepatocellular damage. Elevation of serum levels of these enzymes considered as a key of liver damage. The significant acute heptocellular damage and biliary obstruction were indicated by the high level of ALP, AST and ALT [54].

Paracetamol and its metabolite cause cell membrane and 
mitochondrial injure in liver cells and leads to liberate of $80 \%$ of total hepatic AST enzymes from the mitochondria. Necrosis and membrane injure discharges the enzyme into circulation, therefore it can be measured in serum [55]. The activity of serum marker enzymes is Alanine aminotransferase (ALT), Aspartate aminotransferase (AST) and alkaline phosphatase (ALP) were assessed in serum samples of different groups of rats and is depicted in Table 5.

Table 5. Effect of Aqueous Leaf Extract of Ziziphus jujuba of Serum Enzymes in Different Groups of Rats.

\begin{tabular}{llll}
\hline Treatment Groups & AST (IU/L) & ALT (IU/L) & ALP (IU/L) \\
\hline I - Control & $0.33 \pm 0.02$ & $4.6 \pm 0.421$ & $3.415 \pm 0.085$ \\
II - Paracetamol control & $1.07 \pm 0.03$ & $7.2 \pm 0.523$ & $5.875 \pm 0.554$ \\
III - Paracetamol+Plant extract & $0.435 \pm 0.045$ & $4.83 \pm 0.521$ & $3.769 \pm 0.231$ \\
IV - Silymarin+Paracetamol & $0.365 \pm 0.035$ & $4.94 \pm 0.523$ & $3.591 \pm 0.022$ \\
\hline
\end{tabular}

IU - concentration of enzyme that catalyses the formation of $1 \mu$ mole of product per minute.

The differences in the mean values among the treatment groups are greater than would be expected by chance there is a statistically significant difference $(p=<0.001)$. Values are expressed as mean \pm S.D of 4 rats. Mean values followed by different alphabets be at variance significant [56].

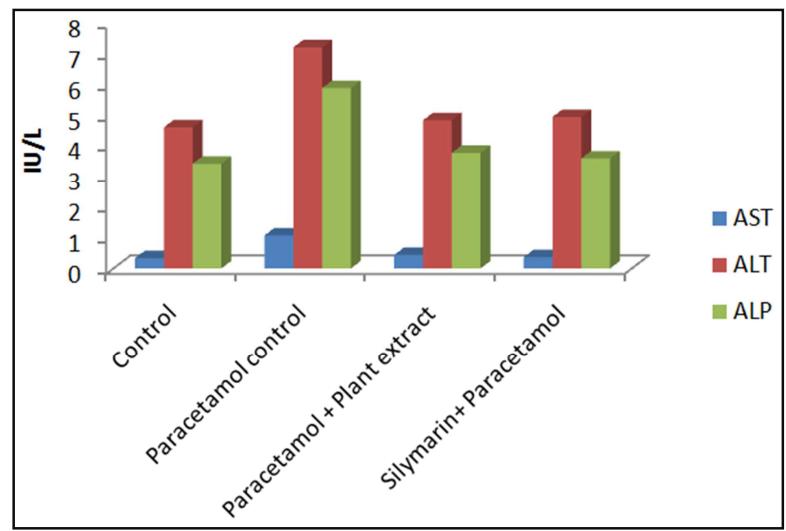

Fig. 1. Effect of Aqueous Leaf Extract of Ziziphus jujuba of Serum Enzymes in Different Groups of Rats.

Chronic administration of paracetamol produced a noticeable elevation of the serum levels of enzymes in treating animals while compared with that of the control group and the standard drug. Treatment with Ziziphus jujuba at a dose of $150 \mathrm{mg} / \mathrm{kg}$ significantly condensed the elevated levels of those enzymes. Treatment with Ziziphus jujuba, decrease the serum levels of aspartate transaminase, alanine transaminase and alkaline phosphatase towards the relevant normal value and standard drug value that is an indication of stabilization of plasma membrane as well as repair of hepatic tissue damage caused by paracetamol.

The activity of antioxidant enzymes such as PPO, SOD, CAT, suggests that the reduction of oxidative stress, it plays a vital role in the mechanism of its hepatoprotective effect. Alkaline phosphatase concentration is related to the functioning of hepatocytes, high level of alkaline phosphatase in the blood serum relates to the increased synthesis of it by the cells lining bile canaliculi usually in reaction to cholestasis and increased biliary pressure [57].

Assessment of Liver Markers Enzymes:

The liver marker enzymes are AST, ALT and ALP are also raised and it has been attributed to the damaged structural integrity of the liver since these are normally located in the cytoplasm and are released into the circulatory system after cell damage [58]. The activities of the liver marker enzymes (AST, ALP and ALT) in the liver samples of the various groups of rats are indicated in Table 6.

Table 6. Effect of Aqueous Leaf Extract of Ziziphus jujuba of Liver Enzymes in Different Groups of Rats.

\begin{tabular}{llll}
\hline TREATMENT GROUPS & AST (IU/L) & ALT (IU/L) & ALP (IU/L) \\
\hline I - Control & $0.18 \pm 0.01$ & $2.5 \pm 0.616$ & $1.428 \pm 0.160$ \\
II - Paracetamol control & $1.29 \pm 0.01$ & $6.3 \pm 0.616$ & $5 \pm 0.121$ \\
$\begin{array}{l}\text { III - Paracetamol + Plant } \\
\text { extract }\end{array}$ & $0.25 \pm 0.01$ & $3.7 \pm 0.616$ & $1.818 \pm 0.144$ \\
IV - Silymarin+ Paracetamol & $0.20 \pm 0.02$ & $2.94 \pm 0.613$ & $1.627 \pm 0.099$ \\
\hline
\end{tabular}

Values are expressed as mean $\pm \mathrm{S}$. D of 4 rats.

The differences in the mean values among the treatment groups are greater than would be expected by chance there is a statistically significant difference $(\mathrm{p}=<0.001)$

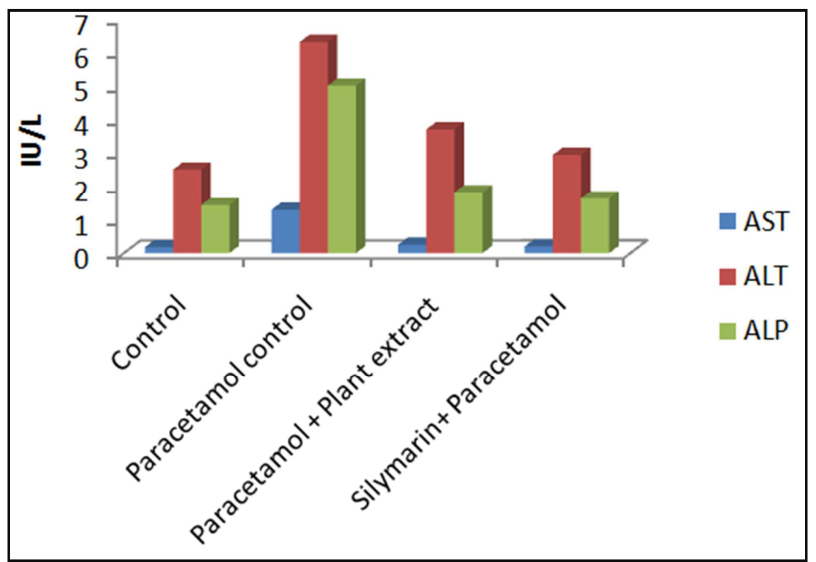

Fig. 2. Effect of Aqueous Leaf Extract of Ziziphus jujuba of Liver Enzymes in Different Groups of Rats.

The liver marker enzymes are ALT, AST and ALP were analysed in the various groups of rats to evaluate the hepatoprotective effect of the aqueous leaf extract of the plant. From the result the activities of all enzymes were found to be higher in group II compared to the control and standard drug. In group III to the levels of the enzymes were decreased when compared with group II. Treatment with aqueous extract of plant sample recovered the injured liver to normal when given at a dose of $(150 \mathrm{mg} / \mathrm{kg}$ b.wt) which indicates that Ziziphus jujuba leaf have intoxicating hepatoprotective effect. The depletion of liver marker enzymes are ALP, AST and ALT in group III rats. This is due to the presence of phytoconstituents in the plant 
extract. The presence of antioxidants such as Glutathione, Peroxidase, Catalase all, act against cellular damage.

\section{Summary and Conclusion}

The extract of Ziziphus jujuba leaves was scrutinized for its phytochemical constituents and Antioxidant activities. These components were used to evaluate the hepatoprotective effect in Swiss albino rats subjected to Paracetamol induced Hepatotoxicity. The study results are summarized as follows:

The studied plants extract restrain antioxidants and hepatoprotective activity through regulatory action on cellular permeability, stability and suppressing oxidative stress. A number of scientific reports designated that certain flavonoids, terpenoids and steroids have a protective effect on the liver due to its antioxidant properties. Phytochemical, plant extract encloses terpenes, flavonoids, alkaloids might play role in hepatoprotective activity.

The enzymatic and non enzymatic antioxidant activity illustrates the maximum activity in the increase concentration of the plant sample $(100 \mu \mathrm{g} / \mathrm{ml})$ and minimum activity was observed in a decrease in concentration of the plant extract. There is a gradual increase in the activity of enzymatic and non enzymatic antioxidant observed through increasing concentration of the plant extract.

The leaf sample was studied beside paracetamol induced hepatotoxicity in experimental rats. When compared to all other groups paracetamol control gains a maximum liver weight. Paracetamol induced animals were treated with aqueous leaf extract proved reduction in the liver weight. Aqueous extract of Ziziphus jujuba appreciably protects against hepatotoxicity as well as oxidative stress.

Chronic administration of paracetamol produced a clear elevation of the serum levels of enzymes in treating animals when compared with that of the control group. Treatment with Ziziphus jujuba decreased the serum levels of aspartate transaminase, alanine transaminase and alkaline phosphatase towards the relevant normal value that is an indication of stabilization of plasma membrane as well as repair of hepatic tissue damage caused by paracetamol. The above changes can be considered as an expression of the purposeful improvement of hepatocytes, which may be caused by a hastened regeneration of parenchymal cells. Similar changes were observed in liver enzymes also.

The results of the present study indicated that under experimental conditions, the aqueous extract of $Z$. jujuba leaves at a dose of $150 \mathrm{mg} / \mathrm{kg}$ has significant hepatoprotective capacity against Paracetamol induced Hepatotoxicity. Hence the aqueous extract of Z. jujuba leaves can be considered as a source of natural antioxidants and effectual hepatoprotective agent.

\section{Further Recommendation}

Further investigation on isolation and characterization of the active compounds responsible for the offered hepatoprotection by aqueous extract of $Z$. jujuba are under way in the laboratory.

\section{Acknowledgement}

The authors thank the authorities of the Avinashilingam Institute for Home Science and Higher Education for Women University (Estd. u/s 3 of UGC Act 1956), Coimbatore-43 for providing the facilities to carry out this research work.

\section{References}

[1] Ahsan, R., Islam M. K., Musaddik, A., Haque, E. (2009). Hepatoprotective Activity of methanol extract of some medicinal plants against carbon tetrachloride induced hepatotoxicity in albino rats. Global Journal of Pharmacology, 3(3): 116-122.

[2] Valko. M, Leibfritz. D, Moncol. J, Cronin. M, Mazur. M, Telser. $\mathrm{J}$, et al., (2007). Free radicals and antioxidants in normal physiological functions and human disease, Int. J. Biochem. Cell Biol. 39 44-84.

[3] Venkat Raji Reddy G., Vijay Kumar R., Rama V., Krishna Reddy M and Narsimha Reddy Y., (2015). Preliminary Hepatoprotective Activity of Medicinal Plant Extracts against Carbon Tetrachloride Induced Hepatotoxicity. In Albino Rats. International Journal Of Recent Scientific Research., Vol. 6, Issue, 7: 4946-4951.

[4] Saleem TS, Chetty SM, Ramkanth S, Rajan VST, Kumar KM, Gauthaman K. (2010) Hepatoprotective herbs: A review. Int J Res Pharma Sci; 1: 1-5.

[5] Chaudhari N. B., Chittam K. P., Patil V. R., et al., (2009). Hepatoprotective activity of Cassia fistula seeds against paracetamol-induced hepatic injury in rats, Arch. Pharm. Sci. Res. 1 (2) 218-221.

[6] Hussain L., Ikram J., Rehman K., Tariq M., Ibrahim M., Akash H., et al., (2014) Hepatoprotective effects of Malva sylvestris L. Against paracetamol-induced hepatotoxicity, Turkish J. Biol. 38 396-402.

[7] Zhang A, Sun H, Wang X (2013). Recent advances in natural products from plants for the treatment of liver diseases. Eur J Med Chem; 63: 570-577.

[8] Arundel C, Lewis JH (2007). "Drug-induced liver disease in 2006". Curr. Opin. Gastroenterol. 23 (3): 244-54.

[9] Furukawa M, Kasajima S (2010). Toxic hepatitis induced by a show-wu-pian, a Chinese herbal preparation. Intern Med. 2010; 49 (15): 1537-40.

[10] Jaeschke H, Gores GJ, Cederbaum AI, Hinson JA, Pessayre D, Lemasters JJ (2002). "Mechanisms of hepatotoxicity". Toxicol. Sci. 65 (2): 166-76.

[11] Wallace JL (2004). "Acetaminophen Hepatotoxicity: No to the rescue” Br. J. Pharmacol. 143 (1): 1-2.

[12] Adil Ramzan (2011). Drug interactions, drug induced hepatotoxicity / Liver Damage-Causes - Risk Factors - dili.

[13] Karunakar Hegde, Arun B Joshi (2010). Preliminary Phytochemical Screening and Antipyretic Activity of Carissa Spinarum Root Extract. Scholar Research Library. 2(3): 255260. 
[14] Gagliano N., Grizzi F., Annoni G., et al., (2007). Mechanism of aging and liver functions, Dig. Dis. Sci. 25 118-123.

[15] Kelava T., Cavar I., Culo F., et al., (2010). Influence of small doses of various drug vehicles on acetaminophen-induced liver injury, Can. J. Physiol. Pharma-col. 88 960-967.

[16] Leffers, H, et al (2010). "Intrauterine exposure to mild analgesics is a risk factor for development of male reproductive disorders in human and rat". Human Reproduction 25 (1): 235 244.

[17] Howtan K et al (2011). Impact of different pack sizes of paracetamol in the United Kingdom and Ireland on intentional overdoses: a comparative study Biomed central.

[18] Lawrence J., Moore E., Port L., Danchin M., Connell T., (2009). "Paracetamol as a risk factor for allergic disorders". The Lancet 373 (9658): 119-119.

[19] Malaya Gupta, Upal Kanti Mazumder, Thangavel Siva Kumar, Periyasamy Gomathi and Ramanathan Sambath Kumar (2004). Antioxidant and Hepatoprotective Effects of Bauhinia racemosa against Paracetamol and Carbon Tetra-chloride Induced Liver Damage in Rats. Iranian Journal of Pharmacology \& Therapeutics IJPT 3: 12-20.

[20] Chaterrjee, T. K., (2000). Medicinal Plants with hepatoprotective properties. Herbal Options. Books and Applied Allied (P) Ltd., Calcutta, pp: 143.

[21] Pingale S. S., and others Pingale et al., (2008). Acute toxicity study for Cissus quadrangularis whole plant powder, Pharmacologyonline, 2: 256-262.

[22] Bhattacharyya D., Pandit S., Mukherjee R., Das N. and Sur T. K. (2003). Hepatoprotective effect of himoliv, a polyherbal formulation in rats. Indian J Physiol Pharmacol; 47 (4): 435 440 .

[23] Yue-Zhong S (1998). Recent natural products based drug development: a pharmaceutical industry perspective. J Nat Prod.; 61: 1053-71.

[24] Pandey M, Debnath M, Gupta S, Chikara SK (2011). Phytomedicine: an Ancient approach turning into future potential source of therapeutics. J Pharmacogn Phytother.; 3(3): 27-37.

[25] Ravishankar B, Shukla VJ (2007). Indian systems of medicine: a brief profile. Afr J Tradit Complement Altern Med.; 4(3): 319-37.

[26] Kaido TL, Veale DJ, Havlik I, Rama DB (1997). Preliminary screening of plants used in South Africa as traditional herbal remedies during pregnancy and labour. J Ethnopharmacol. 55(3): 185-91.

[27] Pradeesh S and Swapna T. S. (2015), In vitro Hepatoprotective activity of a wild medicinal plant from Western Ghats - Bidens Biternata (lour.) Merr. \& Sheriff. International Journal of Research and Reviews in Pharmacy and Applied sciences. Vol. 5 Issue. 2 Pg: 1246-1250.

[28] Jiang J.-G., Huang X.-J., Chen J., Lin Q.-S (2007)."Comparison of the sedative and hypnotic effects of flavonoids, saponins, and polysaccharides extracted from Semen Ziziphus jujube" Natural Product Research 21: 4 (310-320).
[29] Timna Naftali, Haya Feingelernt et al (2008). Ziziphus jujuba extract for the treatment of Chronic Idiopathic Constipation: A controlled clinical trial. Digestion 2008; 78: 224-228.

[30] Shirdel Z, Madani H, Mirbadalzadeh R (2009). Investigation into the hypoglycemic effect of hydroalcoholic extract of Ziziphus jujuba leaves on blood glucose and lipids in Alloxaninduced diabetes in rats. Iranian Journal of Diabetes and Lipid Disorders; pp 13-19.

[31] Mill Goetz P (2009). "Demonstration of the psychotropic effect of mother tincture of Ziziphus jujuba". Phytotherapie7: 1 (3136).

[32] Preeti, Tripathi S (2014). Ziziphus jujuba: A Phytopharmacological review. Int $J$ Res Dev Pharm Life Sci.; 3(3): 959-966.

[33] Prasanna Kumar S. R, Syed Mohammed Basheeruddin Asdaq et al (2009). Protective effect of Ziziphus jujuba fruit extract against Paracetamol and Thioacetamide induced hepatic damage in rats. The Internet Journal of Pharmacology. Volume 7 Number 1.

[34] Raman N (2006). Phytochemical Technique; New Indian Publishing Agencies: New Delhi p. 19.

[35] Iyengar, M. A., (1995). Study of Crude Drugs. 8th ed., Manipal Power Press, Manipal, India. pp 2.

[36] Siddiqui AA and Ali. M (1997). Practical pharmaceutical chemistry. $1^{\text {st }}$ edition. CBS Publishers and Distributors New Delhi. 126-131.

[37] Ayoola G. A., Folawewo A. D., Adesegun S. A., Abioro O. O., Adepoju-Bello A. A., Coker H. A. B (2008). Phytochemical and antioxidant screening of some plants of apocynaceae from South West Nigeria. African Journal of Plant Science Vol. 2 (9), pp. 124-128.

[38] Luck H. (1974). Method in enzymatic analysis-2(ED. Bergmeyer), Acadamic press, NewYork, 885.

[39] Reddy K. P., Subhani S. N., Khan P. A. and Kumar K. V. (1995). Effect of light and benzyl adenine on dark-treated growing rice (oryza sativa) leaves, Changes in peroxidase activity, Plant cell Physiol., 26: 987-994.

[40] Misra H. P and Ridovich A. (1971). The role of superoxide anion in the antioxidant of epinedhrine and a simple assay for superoxide dismutase, J. Biol. chem., 247; 3170-3171.

[41] Esterbaur H., Schwaetz E and Hayan M (1977). A rapid assay for catechol oxidase and laccase using to -nitro-5-thiobenzoic acid, Anl. Bio Chem., 77: 489-494.

[42] Moron M. S., Depierre J. N. and Mannerisk V. C. (1979). Levels of glutathione, glutathione reductase and glutathione-Stransferase activities in rat lung and liver, Biochemical Biophusica acta., 582: 67-68.

[43] Malick C. P and Singh M. B (1980). Estimation of polyphelnols, In: Plant enzymology and histoenzymology, Kalyani Publishers, New Delhi, 286.

[44] Wilkes JM, Clark LE, Herrera JL (2005). Acetaminophen overdose in pregnancy; South Med J; 98(11): 1118-22.

[45] Dargan PI, Jones AL (2002). Acetaminophen poisoning: an update for the intensivist, Crit Care.; 6 (2): 108-10. 
[46] Gupta M, Mazumder UK, Sambath R (2003). Hepatoprotective and antioxidant role of Caesalipinia bonducella on Paracetamolinduced liver damage in rats. Nat Prod Sci,; 9: 186-91.

[47] Reitzman S and Frankel S (1957). A Colorimeter method for the determination of serum glutamic oxalo acetic acid, glutamic pyruvate transaminase. Am J Clin Pathol; 28: 56-63.

[48] King EJ and Armstrong AR (1934). A convenient method for determining serum and bile phosphatase activity. Canad. Med. Ass. J.; 31: 376-381.

[49] Mahajan R. T and Chopda M. Z (2009). "Phyto-pharmacology of Ziziphus jujuba mill - A plant review" Pharmacognosy Reviews 3: 6 (320-329).

[50] Kozer E., Evans S., Barr J., Greenberg R., Soriano I and Bulkowstein M (2003). Glutathione glutathione dependent enzyme and antioxidant status in erythrocytes from children treated with high dose paracetamol. Br. J. Clin. Pharmacol 55: 234-240

[51] Warner D, Sheng H, Batinic-Haberle I (2004). "Oxidants, antioxidants and the ischemic brain". J Exp Biol 207 (Pt 18): 3221-31.

[52] Laszlo Goth (2008). "Catalase Deficiency and Type 2 Diabetes". Diabetes Care 24 (10): e93-e93.
[53] Jafri MA., Subhani MJ., Javed K and Singh S (1999). Hepatoprotective activity of leaves of Cassia occidentalis against paracetamol and ethyl alcohol intoxication in rats. J. Ethnopharmacol 66: 355-361.

[54] Shymal S., Latha P. G., Shine V. J., Suja S. R., Rajasekharan S and Devi T. G (2006). Hepatoprotective effects of Pittosporum neelghrrense Wight and Arn, a popular Indian ethanomedicine. J. Ethnopharmacol., 107: 151-155.

[55] Waring JF; Jolly RA; Ciurlionis R; Lum PY; Praestgaard JT; Morfitt DC; Buratto B; Roberts C et al. (2001). "Clustering of hepatotoxins based on mechanism of toxicity using gene expression profiles". Toxicology and applied pharmacology (1): $28-42$.

[56] Manov I, Motanis H, Frumin I, Iancu TC (2006). "Hepatotoxicity of anti-inflammatory and analgesic drugs: ultrastructural aspects". Acta Pharmacol. Sin. 27 (3): 259-72.

[57] Kanchana. N and Mohamed Sadiq A., (2010). Hepatoprotective effect of plumbago zeylanica on paracetamol induced liver toxicity in rats. International Journal of Pharmacy and Pharmaceutical Sciences, Vol 3, Issue 1.

[58] Xue Z., Feng W., Cao J., Cao D and Jiang W (2009). Antioxidant activity and total phenolic contents in peel and pulp of Chinese jujube (Ziziphus jujuba Mill) fruits. J. Food Biochem. 33: 613-629. 